\title{
Evaluation of Postoperative Anti-nociceptive Efficacy of Intrathecal Dexketoprofen in Rats
}

\author{
Birol Muhammet Er ${ }^{1}$, İsmail Serhat Kocamanoğlu ${ }^{1}$, Ayhan Bozkurt ${ }^{2}$, Sırrı Bilge ${ }^{3}$, Erhan Çetin Çetinoğlu \\ ${ }^{1}$ Department of Anesthesiology, Ondokuz Mayıs University School of Medicine, Samsun, Turkey \\ ${ }^{2}$ Department of Physiology, Ondokuz Mayis University School of Medicine, Samsun, Turkey \\ ${ }^{3}$ Department of Pharmacology, Ondokuz Mayıs University School of Medicine, Samsun, Turkey
}

Background: Some studies have suggested that the intrathecal use of cyclooxygenase enzyme inhibitors provides an anti-nociceptive effect. Therefore, the occurrence of side effects seen in systemic usage can be eliminated.

Aims: The primary objective of this experimental, randomized, controlled trial was to test the hypothesis asserting that intrathecal dexketoprofen trometamol would demonstrate an analgesic effect during postoperative period.

Study Design: Animal experimentation.

Methods: Forty rats were randomized into 4 groups 7 days after intrathecal catheterization; the following drugs were given through catheter lumens: Group Lidocaine (Group L): Lidocaine $20 \mu \mathrm{g}$; Group Lidocaine-Morphine (Group LM): Lidocaine $20 \mu \mathrm{g}$ and morphine $0.5 \mu \mathrm{gr}$; Group LidocaineDexketoprofen (Group LD): Lidocaine $20 \mu \mathrm{g}$ and dexketoprofen trometamol $100 \mu \mathrm{g}$; and Group Dexketoprofen (Group D): Dexketoprofen trometamol $100 \mu \mathrm{g}$. Paw inci- sion was achieved under ether inhalation. To measure analgesic potential, hot plate and tail immersion tests were used as nociceptive tests during the postoperative period.

Results: The mean reaction times detected in groups during hot plate and tail immersion tests were shortest in Group L at $15,30,45,60,75,90,105$, and 120 minutes after start of surgery ( $p<0.01$, all others). In the groups using dexketoprofen, as in the morphine group, longer reaction times were detected than in the lidocaine group at all measurement times except 120 minutes $(\mathrm{p}<0.01)$.

Conclusion: Intrathecal dexketoprofen in the optimal perioperative pain management is effective, and can be administered as an adjuvant in clinics after neurotoxicity studies in animals, and effective dose studies in volunteers.

Keywords: Dexketoprofen trometamol, injection, pain, postoperative, postoperative complications, spinal
Even though beneficial effects of cyclooxygenase enzyme (COX) inhibitors during the perioperative period are apparently known, debates on their usage are ongoing because of their potential risks, such as gastrointestinal mucosa and renal tubular damages, and the induction of platelet dysfunction (1). Some studies have suggested that the intrathecal (IT) use of COX inhibitors provides anti-nociceptive effect, and decrease in hyperalgesia; also, the occurrence of side effects seen in systemic usage can be eliminated $(2,3)$. It has been indicated that nonsteroidal anti-inflammatory drugs (NSAIDs), which can spontaneously pass through the blood- brain barrier or be given via the IT route, demonstrate a central analgesic effect (4).

Dexketoprofen trometamol is a non-selective NSAID belonging to the aryl-proprionic acid group which is an active S-enantiomer of racemic ketoprofen. Owing to its rapid absorption, and the onset of its effect immediately after its administration, it is preferred for the alleviation of acute pains. In various animal studies, the analgesic effectiveness of ketoprofen has been attributed to its dexketoprofen component $(5,6)$. Dexketoprofen trometamol, at the peripheral level, inhibits the release of prostaglandins from the site of the lesion, and subsequently

Address for Correspondence: Dr. İsmail Serhat Kocamanoğlu, Department of Anesthesiology, Ondokuz Mayıs University School of Medicine, Samsun, Turkey Phone: +90 5056177640 e-mail: serhatk@omu.edu.tr

Received: 4 December $2014 \quad$ Accepted: 30 September $2015 \cdot$ DOI: 10.5152/balkanmedj.2016.140986

Available at www.balkanmedicaljournal.org 
prevents the stimulation of pain receptors. Also, its central effects block activities of COX, leading to a decrease in its central sensitization effect, and inhibit painful stimuli from reaching the upper levels of the nervous system.

Intrathecal dexketoprofen trometamol use has no place in clinical practice. In studies performed using NSAIDs, controversial results have been obtained regarding its IT effectiveness. Starting from this perspective, we aimed to test the hypothesis asserting that IT dexketoprofen trometamol would demonstrate an analgesic effect during the postoperative period.

\section{MATERIALS AND METHODS}

Ethics approval for this prospective, experimental study (2009/76) was granted by Animal Ethics Committee of Animal Ethics Committee of Ondokuz Mayıs University Faculty of Medicine, Medical and Surgical Research Centre (Chairperson Dr. Fersat Kolbakir) on 23 November 2009. This study was performed using forty 12-16 month-old Sprague-Downey rats weighing 250-300 $\mathrm{g}$ from the Medical and Surgical Research Centre of Ondokuz Mayıs University, Faculty of Medicine. During the study, all rats were kept in separate cages under their natural environments (12 alternate hours of light and darkness, at $21 \pm 2^{\circ} \mathrm{C}$ ).

Rats were starved from the night before surgery, and given $100 \mathrm{mg} / \mathrm{kg}$ i.p. ketamine (Ketalar, Pfizer; İstanbul, Turkey) anesthesia on the day of the experiment. After the induction of anesthesia, rats were fixed in the prone position on a stereotaxy device. After sterilization of the operative site, an occipitocervical incision was made exploring the atlantooccipital membrane. This membrane was perforated to see the flow of cerebrospinal fluid. Then, as described by Yaksh and Rudy (7), a stylet was inserted into a $28 \mathrm{G}$ micro catheter (Portex ${ }^{\circledR}$, Microcatheter system for continuous spinal anesthesia, Smith Medical; Ashford, UK) used for continuous spinal anesthesia, and advanced $8 \mathrm{~cm}$ towards the caudal direction. After placement of the catheter, the incised muscular and cutaneous layers were sutured; the external end of the catheter was fixed with dental acrylic sutures (Figure 1). Using a Hamilton injector, catheter lumen was flushed with $0.01 \mathrm{~mL} \mathrm{SF}$ (death space volume), and plugged. All rats received antibiotherapy before and after surgical interventions.

To measure analgesic potential, hot plate and tail immersion tests were used as nociceptive tests. These tests were performed by a researcher blinded to the contents of the injector.

\section{Hot plate test}

Rats were placed on a hot plate (Bioseb; Florida, USA) with a thermostatic base maintaining its mean temperature at

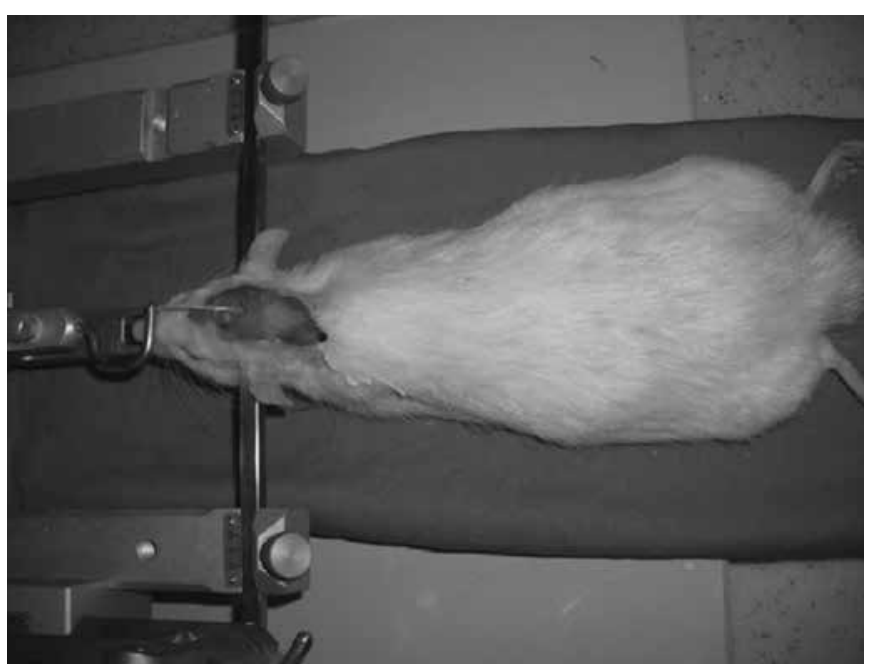

FIG. 1. Spinal catheter fixed to the skin

$55 \pm 0.5^{\circ} \mathrm{C}$, and time to the onset of rat's reaction to hot plate was quantified. Licking or lifting hind paws was considered a positive reaction, and the time interval between rats' first contact with the hot plate and their positive reactions was recorded. To prevent tissue damage, time to retain the rat on the hot plate was limited to 60 seconds (cut-off time).

\section{Tail immersion test}

The tails of rats were half-dipped into hot water kept constant at a mean temperature of $55 \pm 0.5^{\circ} \mathrm{C}$; tail-flick or verbal reaction was considered a positive reaction, and the time interval between tail immersion and a positive reaction was recorded. To prevent tissue damage, retention time of the tail immersed in water was limited to 15 seconds (cut-off time).

Baseline value of each nociceptive test was calculated as an arithmetic mean of 3 successive measurements at 7 seven days after catheter insertion, before randomization.

Forty rats were randomized using computer generated random number table into 4 groups 7 days after catheterization; 10 rats were included in each group. The following drugs were given through catheter lumens:

Group Lidocaine (Group L): lidocaine (Aritmal, Osel ilac; İstanbul, Turkey) $20 \mu \mathrm{g}(5 \mu \mathrm{L})$, and saline $(5 \mu \mathrm{L})$

Group Lidocaine-Morphine (Group LM): lidocaine $20 \mu \mathrm{g}(5$ $\mu \mathrm{L}$ ), and morphine (Morphine, Galen ilac; İstanbul, Turkey) $0.5 \mu \mathrm{gr}(5 \mu \mathrm{L})$

Group Lidocaine-Dexketoprofen (Group LD): lidocaine

$20 \mu \mathrm{g}(5 \mu \mathrm{L})$, and dexketoprofen trometamol (Arveles, İbrahim Ethem Ulugay; İstanbul, Turkey) $100 \mu \mathrm{g}(5 \mu \mathrm{L})$

Group Dexketoprofen (Group D): dexketoprofen trometamol $100 \mu \mathrm{g}(5 \mu \mathrm{L})$, and saline $(5 \mu \mathrm{L})$

Also, the amount of saline equal to the dead space volume $(0.01 \mathrm{~mL})$ was flushed via the external end of the catheters. In- 
trathecal placement of catheter was corrected with the prolongation of times of nociceptive tests. If there were no changes compare to the baseline values, the rat was excluded from the study and calculations.

The time interval between the delivery of the drug through a catheter and the onset of surgery was standardized as $10 \mathrm{~min}$ utes. To achieve immobility and surgical anesthesia in regions where spinal analgesia could not be accomplished, short-term inhalation anesthesia was induced using a cylindrical apparatus containing a swab dipped in a volatile ether solution. Ether inhalation time ranged between 30 and 60 seconds, and after the induction of sedation, surgery (paw incision) was started. As described by Brennan et al. (8), after surgical cleansing of the right hind paw with $70 \%$ alcohol, a longitudinal $1 \mathrm{~cm}$ incision was made extending from the corner of the heel to a distance $0.5 \mathrm{~cm}$ away towards the nails. Through this incision, plantar muscles were exposed, cut lengthwise, and the incision was sutured with 5.0 silk.

Nociceptive tests were applied at 15, 30, 45, 60, 75, 90, 105, and 120 minutes after the start of surgery. Before initiating nociceptive tests, sedation and motor function scores of all rats were rated.

Evaluation of sedation: degree of sedation was rated between " 0 " and " 2 " based on the severity of reactions of the rats subjected to auditory and tactile stimuli (Table 1).

Evaluation of motor functions was performed using placing-stepping and righting reflexes.

Placing-Stepping Reflex: Rats begin stepping movements after stimulating dorsum of either hind paw.

Righting Reflex: An animal placed horizontally with its back on the table will normally show an immediate coordinated twisting of the body around its longitudinal axis to regain its normal position on its feet. Responses elicited during both reflex tests were scored as 0,1 , and 2 (Table 2).

Reaction times measured during hot plate and tail immersion tests were compared with baseline values and maximum possible effect (MPE\%) was calculated.

TABLE 1. Immunohistochemical results of SCCs and KAs

\begin{tabular}{ll}
\hline SEDATION SCORES & \\
\hline Active & 0 \\
Tendency to somnolence, response to stimuli & 1 \\
Sleepy, refractory to stimuli & 2 \\
\hline SCC: squamous cell carcinoma; KA: keratoacanthoma
\end{tabular}

TABLE 2. Motor Function Scale scores

\begin{tabular}{ll}
\hline Normal motor response & 2 \\
Slower than normal motor response & 1 \\
No motor response & 0 \\
\hline
\end{tabular}

MPE $\%=100 \times[$ (test value-baseline value)/(cut-off time-baseline value)].

Accordingly, we have the opportunity to compare percent changes developed secondary to drug effects that were influential during postoperative test.

\section{Sample size analysis}

Sample size was determined based on previously performed IT ketoprofen study (9) with a statistical power of $80 \%(\alpha=5 \%$, $\beta=20 \%$ ). In this study, statistical calculations made in Minitab 14 software statistical program using postoperative mean pain scores obtained in ketoprofen and control group $(8.1 \pm 1.3 \mathrm{vs}$. $14.7 \pm 1.3)$. The results indicated that a minimum number of 3 rats in each study group was sufficient with which to conduct statistical analysis. Since we used drugs belonging to the same group but with different formulations, we included 10 experimental animals in each group to increase the statistical power of the study to over $80 \%$.

\section{Statistical analysis}

Data were transferred into SPSS 16.0 program (SPSS Statistic for Windows, Version 16.0, SPSS Inc.; Chicago, IL, USA), and expressed as mean \pm standard deviation (SD). Concordance of data to normal distribution was analyzed using Shapiro-Wilk test. Kruskal-Wallis test was used because of the inability to ensure parametric conditions in intergroup comparisons. For pairwise comparisons of different parameters, Mann-Whitney test with Bonferroni correction was used. $\mathrm{P}<0.05$ was considered to be significant.

\section{RESULTS}

During catheterization, respiratory arrest occurred in 1 rat, while 3 rats had arrest after a bleeding episode emerged during the insertion of the catheter into the spinal space. After the development of motor deficit in 8 rats and deterioration in the general health status of 3 rats following catheterization procedure, these rats were excluded from the study. In place of these rats, new rats were included in the study to take the study population up to 40 rats.

Before nociceptive tests, the mean sedation score of all rats was found to be " 0 ", while the mean motor function assessment score was 1 in Groups L and LM, and 2 in dexketoprofen groups. At the time of the second measurement (at 30 $\mathrm{min}$ ), the motor function score of all rats was "2". The mean operative time was $5.27 \pm 1.06$ minutes without any difference between groups. 
TABLE 3. Mean reaction times (second) of the groups in the hot plate test

\begin{tabular}{lccccccccc}
\hline Time (min) & Basal & $\mathrm{t} 1$ & $\mathrm{t} 2$ & $\mathrm{t} 3$ & $\mathrm{t} 4$ & $\mathrm{t} 5$ & $\mathrm{t} 6$ & $\mathrm{t} 7$ & $\mathrm{t} 8$ \\
\hline Group L & $15.52 \pm 0.8$ & $20.42 \pm 2.9$ & $21.35 \pm 2.5$ & $20.84 \pm 2.7$ & $18.09 \pm 2.7$ & $15.26 \pm 2.2$ & $14.28 \pm 1.7$ & $16.40 \pm 1.1$ & $15.20 \pm 0.9$ \\
Group LM & $15.60 \pm 1.1$ & $43.3 \pm 10.6$ & $48.19 \pm 9.5$ & $49.20 \pm 7.9$ & $49.90 \pm 7.2$ & $38.9 \pm 12.4$ & $27.73 \pm 7.7$ & $18.44 \pm 5.0$ & $14.26 \pm 0.9$ \\
Group LD & $15.88 \pm 1.9$ & $29.13 \pm 6.0$ & $39.56 \pm 8.4$ & $42.05 \pm 7.4$ & $46.55 \pm 6.8$ & $38.69 \pm 9.7$ & $25.47 \pm 7.3$ & $18.64 \pm 4.2$ & $15.43 \pm 2.2$ \\
Group D & $16.18 \pm 1.0$ & $24.82 \pm 2.8$ & $35.86 \pm 5.5$ & $38.43 \pm 7.6$ & $39.56 \pm 5.6$ & $30.77 \pm 7.5$ & $21.04 \pm 7.4$ & $16.65 \pm 4.5$ & $14.18 \pm 1.1$ \\
p & 0.467 & $0.000^{1,2}$ & $0.000^{1,3}$ & $0.000^{1}$ & $0.000^{1,4}$ & $0.000^{1}$ & $0.000^{1}$ & $0.002^{5}$ & $0.003^{6}$ \\
\hline
\end{tabular}

Group L: Group Lidocaine, Group LM: Group Lidocaine-Morphine, Group LD: Group Lidocaine-Dexketoprofen, Group D: Group Dexketoprofen; t1: 15 minute (min); t2: 30 min; t3: 45 min; t4: 60 min; t5: 75 min; t6: 90 min; t7: 105 min; t8: 120 min; 1: Group L, lower than others; 2: Group LM, higher than others; 3: Group LM, higher than Group D; 4: Group LM, higher than Group D; 5: Group L, lower than Groups LM and LD; 6: Group LD, higher than Group L

TABLE 4. Mean reaction times (second) of the groups in the tail immersion test

\begin{tabular}{|c|c|c|c|c|c|c|c|c|c|}
\hline Time (min) & Basal & $\mathrm{t} 1$ & $\mathrm{t} 2$ & $\mathrm{t} 3$ & t4 & t5 & t6 & $\mathrm{t} 7$ & t8 \\
\hline Group L & $3.92 \pm 0.36$ & $5.55 \pm 0.93$ & $5.51 \pm 0.72$ & $5.56 \pm 1.01$ & $4.37 \pm 0.84$ & $3.77 \pm 0.65$ & $3.42 \pm 0.40$ & $3.23 \pm 0.27$ & $3.09 \pm 0.23$ \\
\hline Group LM & $3.58 \pm 0.63$ & $8.36 \pm 2.24$ & $9.61 \pm 2.93$ & $9.48 \pm 2.30$ & $7.68 \pm 1.53$ & $5.46 \pm 0.78$ & $4.07 \pm 0.70$ & $3.35 \pm 0.45$ & $3.17 \pm 0.48$ \\
\hline Group LD & $4.16 \pm 0.73$ & $6.11 \pm 1.67$ & $7.51 \pm 1.36$ & $7.78 \pm 1.95$ & $7.84 \pm 1.80$ & $5.57 \pm 1.46$ & $4.37 \pm 0.77$ & $3.66 \pm 0.60$ & $3.54 \pm 0.56$ \\
\hline Group D & $3.51 \pm 0.42$ & $6.59 \pm 2.08$ & $7.34 \pm 1.47$ & $7.40 \pm 2.19$ & $6.58 \pm 0.78$ & $5.65 \pm 0.82$ & $4.00 \pm 0.70$ & $3.21 \pm 0.46$ & $2.83 \pm 0.17$ \\
\hline $\mathrm{p}$ & 0.059 & $0.006^{1}$ & $0.000^{2,3}$ & $0.001^{2}$ & $0.000^{2}$ & $0.001^{2}$ & $0.012^{2}$ & 0.186 & 0.08 \\
\hline
\end{tabular}

t3: $45 \mathrm{~min}$; t4: $60 \mathrm{~min}$; t5: $75 \mathrm{~min}$; t6: $90 \mathrm{~min}$; $7: 105 \mathrm{~min}$; t8: $120 \mathrm{~min}$; 1: Group LM, higher than others; 2: Group L, lower than others; 3: Group LM, higher than Group D

Baseline mean nociceptive test values are shown in Tables 3 and 4 . No statistically significant difference was found between baseline values measured in groups during hot plate and tail-immersion tests before IT injection ( $\mathrm{p}=0.467$ and $\mathrm{p}=0.059$, respectively).

\section{Hot plate test}

Mean reaction times detected in groups during hot plate tests and calculated MPE values are shown in Table 3 and Figure 2, respectively. At $15 \mathrm{~min}$, the mean MPE value of Group $\mathrm{L}$ was found to be lower than other groups $(\mathrm{p}=0.000$; $p=0.003 ; p=0.005$, respectively). The mean MPE value of Group LM was also found to be higher than all other groups ( $\mathrm{p}=0.004$ and $\mathrm{p}=0.000$, respectively). At $30 \mathrm{~min}$, the mean MPE value of Group $L$ was found to be lower than other groups ( $\mathrm{p}=0.000$, all others). Besides, the mean MPE value of Group LM was noted to be even higher than that of Group $\mathrm{D}(\mathrm{p}=0.008)$. At $45 \mathrm{~min}$, the mean MPE value of Group L was found to be lower than that of other groups $(p=0.000$, all others). At $60 \mathrm{~min}$, the mean MPE value of Group L was lower than other groups ( $p=0.000$, all others). Besides, the mean MPE value of Group LM was higher than that of Group $\mathrm{D}(\mathrm{p}=0.002)$. At $75 \mathrm{~min}$ and $90 \mathrm{~min}$, mean MPE values of Group L were found to be lower than those of other groups ( $p=0.000$, all others). At $105 \mathrm{~min}$, the mean MPE value of Group L was shown to be decreased when compared with that of Groups LM and LD ( $\mathrm{p}=0.000$, others). At $120 \mathrm{~min}$, the mean MPE value of Group LD was higher than that of Group L ( $\mathrm{p}=0.000)$.

\section{Tail immersion test}

The mean reaction times in tail immersion tests of groups, and calculated MPE percentages are shown in Table 4, and Figure 3 , respectively. At $15 \mathrm{~min}$, the mean MPE value of Group LM was found to be higher than other groups $(p=0.000 ; p=0.004$; $\mathrm{p}=0.000$, respectively). At $30 \mathrm{~min}$, the mean MPE value of Group $\mathrm{L}$ was detected to be lower than other groups $(\mathrm{p}=0.000 ; \mathrm{p}=0.001$; $\mathrm{p}=0.001$, respectively). Besides, the mean MPE value of Group LM was higher than that of Group D ( $\mathrm{p}=0.008)$. At $45 \mathrm{~min}$, the mean MPE value of Group L was decreased when compared with other groups $(\mathrm{p}=0.000 ; \mathrm{p}=0.002 ; \mathrm{p}=0.001$, respectively). At $60 \mathrm{~min}$, the mean MPE value of Group L was found to be lower than other groups ( $\mathrm{p}=0.000$, all others). At $75 \mathrm{~min}$, the mean MPE value of Group L was detected to be decreased relative to other groups ( $\mathrm{p}=0.000 ; \mathrm{p}=0.007 ; \mathrm{p}=0.000$, respectively). At 90 $\mathrm{min}$, the mean MPE value of Group $\mathrm{L}$ was noted to be lower than other groups ( $\mathrm{p}=0.001 ; \mathrm{p}=0.003 ; \mathrm{p}=0.003$, respectively).

\section{DISCUSSION}

Many studies have indicated that NSAIDs have analgesic effects comparable to opioids without resulting in opioid-like side effects $(10,11)$. A recently published review analyzed 35 randomized clinical studies encompassing 6380 patients where 3381 of them used dexketoprofen trometamol. In 29 of these 30 clinical studies, the drug was seen to be as effective as other analgesics (ketoprofen, paracetamol/codeine, etc.) with known efficacy (12). 


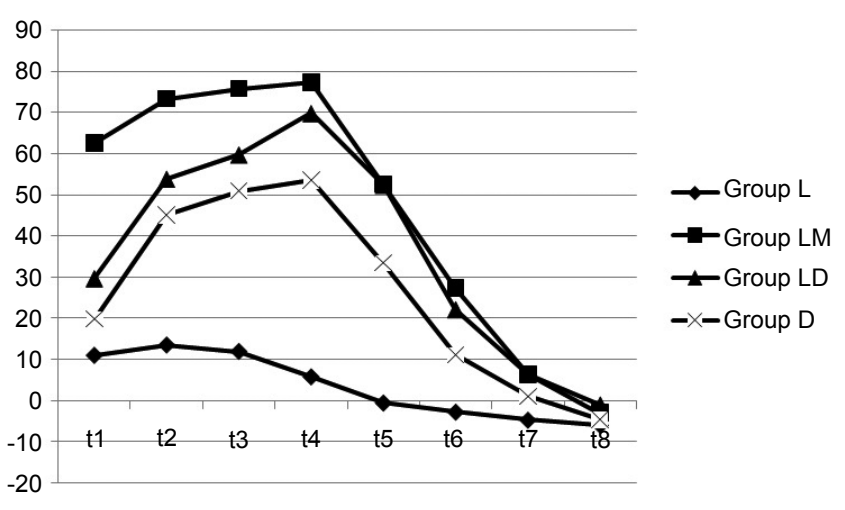

MPE

FIG. 2. Maximum Possible Effects (MPE \%) (mean) of the groups at mean reaction times in the hot plate test.

Group L: Group Lidocaine; Group LM: Group Lidocaine-Morphine; Group LD: Group Lidocaine-Dexketoprofen; Group D: Group Dexketoprofen; t1: 15. minute (min); t2: 30. min; t3: 45 min; t4: 60. min; t5: 75. min; t6: 90. min; t7: 105. min, t8: $120 . \mathrm{min}$

Although the benefits of the use of NSAIDs during the perioperative period are clearly known, relevant debates have been conducted because of their potential risks with regard to gastrointestinal mucosal and renal tubular damage, and the induction of platelet dysfunction, as well as their inadequate efficacy relative to opioids (13). It has been conceived that prophylaxis against the apparent side effects of systemic usage of COX inhibitors can be accomplished by administering lower doses of these drugs via the IT route. In previously conducted studies, it was asserted that the IT administration of various non-selective COX inhibitors such as acetylsalicylic acid, ibuprofen, and ketoralac could alleviate hyperalgesia, and they could also be used at doses 100- to 300-fold lower than required for systemic usage without the development of any side effects seen in systemic usage $(2,14)$.

COX-1 and COX-2 have been shown to be incorporated in the structure of the spinal cord (15-17). Various studies demonstrated that COX-2 inhibitors given via IT route are effective in alleviating mechanic allodynia, and thermal hyperalgesia secondary to inflammatory processes (2). On the contrary, in the postoperative pain model created by incisions made on the hind paws of rats, increase in the levels of COX-1 was observed in the spinal cord, and only COX-1 inhibitors could provide an analgesic effect (17).

Intrathecal administration of the non-selective COX inhibitor indomethacin has been shown to inhibit nociceptive windup reflex evoked by electrical stimulation of the sural nerve (15). Similarly, ketoprofen inhibits c-fiber activity in rats (18). Lopez-Munoz et al. (19) exposed rats to oral or intracerebroventricular dexketoprofen, and demonstrated that the drug had similar anti-nociceptive efficacy via both routes of adminis-

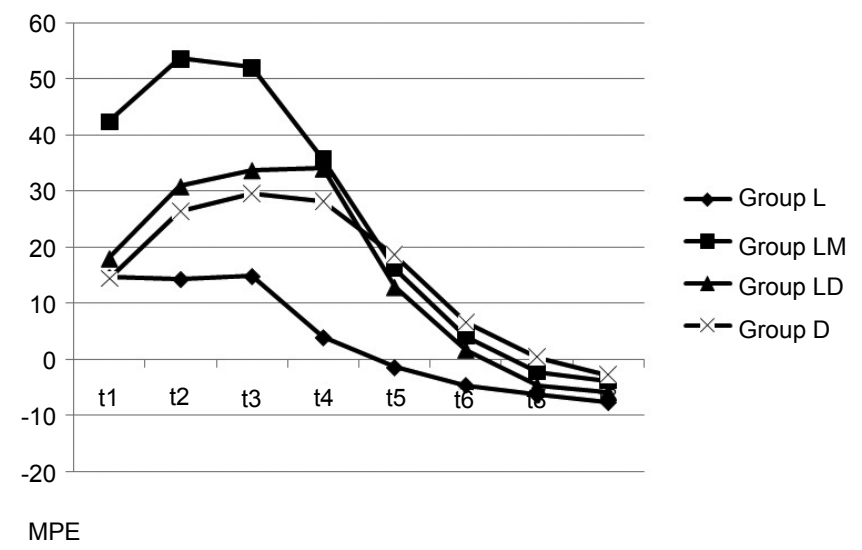

FIG. 3. Maximum Possible Effects (MPE \%) (mean) of the groups at mean reaction times in the Tail Immersion Test.

Group L: Group Lidocaine; Group LM: Group Lidocaine-Morphine; Group LD: Group Lidocaine-Dexketoprofen; Group D: Group Dexketoprofen; t1: 15. minute (min); t2: 30. min; t3: 45 min; t4: 60. min; t5: 75. min; t6: 90. min; t7: 105. min; t8: $120 . \min$

tration. They demonstrated that in the peripheral inflammation model induced by carrageenan injection into the plantar surface of the hind paw of a rat, levels of COX-2 mRNA increased more significantly relative to COX-1 mRNA. However, in the postoperative pain model constructed by incising the hind paws of rats, levels of COX-1 mRNA in the spinal cord increased more significantly (20). Zhu et al. (21) intrathecally administered ketorolac, SC-560 (a COX-1 selective inhibitor) or NS-398 (a COX-2 selective inhibitor) 15 minutes before surgery, and found that in response to mechanical stimulation, ketoralac and SC-560 increased the threshold of the paw-flick withdrawal test, while NS-398 did not change this threshold. In thermal hyperalgesia induced by the injection of carrageenan into the paw of rats, SC-560 was found to be ineffective contrary to NS-398. In another study, in a rat model of tonic, chemical pain, after the concomitant IT usage of morphine, and non-selective NSAIDs, emergence of a synergic effect was demonstrated (22).

Miranda et al. (22) induced a chemical pain model by the acetic acid writhing test, and calculated an $\mathrm{ED}_{50}$ value of 0.86 $\mathrm{mg} / \mathrm{kg}$ for an anti-nociceptive effect of IT use. Ossipov et al. (23) used $100 \mu \mathrm{g}$ IT dexketoprofen after paw incision in the hot plate test. We also have taken all of these studies into consideration, and used IT dexketoprofen trometamol at a dose of $100 \mu \mathrm{g}$. Since in our study we wanted to construct a surgical model suitable for spinal anesthesia, we used IT lidocaine in three groups. In our study, we wanted a short-term spinal anesthesia, and used lower doses of lidocaine which could not inhibit the movements of rats, and also paw withdrawal reflex. In fact, motor function assessment score was only ' 1 ' in groups who received lidocaine injections before the tests. A 
partial motor block was observed which impaired the quality of gait, but did not prevent responses of rats to painful stimuli; at the time of the second measurement, the motor functions of all groups recovered completely.

In an experimental study in rats, $\mathrm{ED}_{50}$ of IT morphine was calculated as $1.6 \mu \mathrm{g} / \mathrm{kg}$ (24). Martin et al. (25) found $\geq 0.5 \mu \mathrm{g}$ morphine to be effective in mechanic hyperalgesia induced following paw incision in rats. We also used morphine at an IT dose of $0.5 \mu \mathrm{g}$ MPE values of morphine in the hot plate, and tail immersion tests indicated that its analgesic effect emerged between 15 and 105 minutes after its application. The decline in MPE values after $75 \mathrm{~min}$ in the hot plate and $60 \mathrm{~min}$ in the tail immersion test demonstrated that the analgesic effect decreases after 60 minutes of application.

Maximum possible effect values in the hot plate test suggested that although analgesic effect of dexketoprofen is inferior to morphine at $15 \mathrm{~min}$, whereas from $30 \mathrm{~min}$ onwards, it equaled that of morphine. The peak value was achieved at $60 \mathrm{~min}$ in both dexketoprofen groups. Similarly, in the tail immersion test from $30 \mathrm{~min}$ up to $105 \mathrm{~min}$, dexketoprofen demonstrated an analgesic effect that was similar to morphine.

Spofford et al. (9) induced postoperative pain model by incising a hind paw, just like we did in our study, and administered $150 \mu \mathrm{g}$ ketoprofen IT 30 minutes before surgery. For the first hour, they observed pain-avoidance behavior of rats, while 2 hours after surgery they induced thermal hyperalgesia with hot plate test, and mechanic hyperalgesia with von Frey filament method to investigate analgesic efficacy. In these tests, the authors found ketoprofen to be ineffective in alleviating both thermal and mechanic hyperalgesia, while the drug was effective in inducing pain-avoidance behavior as a reaction against post incisional non-evoked pain. Because of the continuality of pain avoidance behavior, and lack of stimulation, they thought that ketoprofen might be effective in postoperative rest pain. Pain-avoidance scores 30 minutes after IT administration on postoperative days 1 and 2 were significantly lower compared with the control group. However, Zhu et al. (21) intrathecally administered $50 \mu \mathrm{g}$ ketorolac, and $100 \mu \mathrm{g}$ SC 56015 minutes before paw incision, and found these drugs to be effective in mechanic hyperalgesia test at the postoperative second hour. However, IT dexketoprofen given 10 minutes before surgery demonstrated an analgesic effect in pain tests beginning from $15 \mathrm{~min}$ and extending up to 105 min postoperatively. Martin et al. (25) injected IT ketoralac to laparotomized rats with incised paws in the mechanic pain model, and found that a dose of $50 \mu \mathrm{g}$ exerted a marked effect, and when added to morphine it augmented the effect of morphine by up to 3.5 times.
Ossipov et al. (23) induced thermal pain in a hot plate test after paw incision, and concluded that IT R-ketoprofen has only anti-allodynic, rather than anti-nociceptive effects, while on the contrary, dexketoprofen (S-ketoprofen) has only anti-nociceptive effects. In the dexketoprofen trometamol group, we detected morphine-like anti-nociceptive efficacy at $30 \mathrm{~min}$ in the tail immersion test performed following surgical procedure. Mazario et al. (26) evaluated the response of a single motor unit to electrical stimulation in healthy rats without inflammation, and demonstrated that dexketoprofen trometamol was as potent as $\mu$ opioid fentanyl in depressing wind-up, and spinal cord reflexes. This result supports the conclusion of our study.

In conclusion, we foresee that the IT usage of the non-opioid analgesic drug dexketoprofen in optimal perioperative pain management is effective, and that it can be administered as an adjuvant in order to be used as an alternative drug or with the intention of decreasing required opioid dosage. However, neurotoxicity studies and effective dose studies in volunteers must be conducted in the future.

Ethics Committee Approval: Ethics committee approval was received for this study from Animal Ethics Committee of Ondokuz Mayıs University School of Medicine, Medical and Surgical Research Centre.

\section{Informed Consent: N/A.}

Peer-review: Externally peer-reviewed.

Author contributions: Concept - B.M.E., İ.S.K.; Design - B.M.E., İ.S.K., A.B., S.B.; Supervision - İ.S.K.; Resource - B.M.E., İ.S.K., A.B., S.B.; Materials - B.M.E., İ.S.K., A.B., S.B.; Data Collection and/or Processing - B.M.E.; Analysis and/or Interpretation - B.M.E., İ.S.K., E.C.C.; Literature Search - B.M.E., İ.S.K.; Writing - B.M.E., İ.S.K.; Critical Reviews - B.M.E., İ.S.K., A.B., S.B., E.C.C.

Acknowledgements: Authors would like to thank Assistant Professor Fatih Ilkaya, MD, for the contribution to the preparation of rats, and Gurkan Kazanci for editing language of the manuscript.

Conflict of Interest: No conflict of interest was declared by the authors.

Financial Disclosure: All financial and material support for this research and work were Research Founding of Department of Anesthesiology of Ondokuz Mayıs University.

\section{REFERENCES}

1. Han JB, Keller EE, Grothe RM. Postoperative gastrointestinal bleeding in orthognathic surgery patients: its estimated prevalence and possible association to known risk factors. J Oral Maxillofac Surg 2014;72:2043-51. [CrossRef] 
2. Yaksh TL, Dirig DM, Conway CM, Svensson C, Luo D, Isakson $\mathrm{PC}$. The acute antihyperalgesic action of NSAIDs and release of spinal PGE2 is mediated by the inhibition of constitutive spinal COX-2 but not COX-1. J Neurosci 2001;21:5847-53.

3. Choi CH, Kim WM, Lee HG, Jeong CW, Kim CM, Lee SH, et al. Roles of opioid receptor subtype in the spinal antinociception of selective cyclooxygenase 2 inhibitor. Korean J Pain 2010;23:236-41. [CrossRef]

4. McCormack K. The spinal actions of nonsteroidal anti-inflammatory drugs and the dissociation between their anti-inflammatory and analgesic effects. Drugs 1994;47:28-45. [CrossRef]

5. Rodríguez MJ, Arbós RM, Amaro SR. Dexketoprofen trometamol: clinical evidence supporting its role as a painkiller. Expert Rev Neurother 2008;8:1625-40. [CrossRef]

6. Cabre F, Fernandez MF, Calvo L, Ferrer X, Garcia ML, Mauleon D. Analgesic, antiinflammatory and antipyretic effects of $\mathrm{S}(+)-$ ketoprofen in vivo. J Clin Pharmacol 1998;38:3S-10S.

7. Yaksh TL, Rudy TA. Analgesia mediated by a direct spinal action of narcotics. Science 1976;192:1357-8. [CrossRef]

8. Brennan TJ, Vandermeulen EP, Gebhart GF. Characterization of a rat model of incisional pain. Pain 1996;64:493-501. [CrossRef]

9. Spofford CM, Ashmawi H, Subieta A, Buevich F, Moses A, Baker M, et al. Ketoprofen produces modality-specific inhibition of pain behaviors in rats after plantar incision. Anesth Analg 2009;109:1992-9. [CrossRef]

10. Derry S, Derry CJ, Moore RA. Single dose oral ibuprofen plus oxycodone for acute postoperative pain in adults. Cochrane Database Syst Rev 2013;6:CD010289. [CrossRef]

11. Ding Y, White PF. Comparative effects of ketorolac, dezocine and fentanyl as adjuvants during outpatient anesthesia. Anesth Analg 1992;75:566-71. [CrossRef]

12. Moore RA, Barden J. Systematic review of dexketoprofen in acute and chronic pain. BMC Clin Pharmacol 2008;8:11. [CrossRef]

13. Souter A, Fredman B, White PF. Controversies in the perioperative use of nonsteroidal antiinflammatory drugs. Anesth Analg 1994;79:1178-90. [CrossRef]

14. Malmberg AB, Yaksh TL. Hyperalgesia mediated by spinalglutamate or substance P receptor blocked by spinal cyclooxygenase inhibition. Science 1992;257:1276-9. [CrossRef]

15. Willingale HL, Gardiner NJ, McLymont N, Giblett S, Grubb BD. Prostanoids synthesized by cyclooxygenase isoforms in rat spinal cord and their contribution to the development of neuronal hyperexcitability. Br J Pharmacol 1997;122:1593-604. [CrossRef]
16. Ebersberger A, Grubb BD, Willingale HL, Gardiner NJ, Nebe J, Schaible HG. The intraspinal release of prostaglandin E2 in a model of acute arthritis is accompanied by an up-regulation of cyclo-oxygenase-2 in the spinal cord. Neuroscience 1999;93:775-81. [CrossRef]

17. Zhu X, Conklin D, Eisenach JC. Cyclooxygenase-1 in the spinal cord plays an important role in postoperative pain. Pain 2003;104:15-23. [CrossRef]

18. Bustamante D, Paeile C, Willer JC, Le Bars D. Effects of intrathecal or intracerebroventricular administration of nonsteroidal antiinflammatory drugs on a C-fiber reflex in rats. J Pharmacol Exp Ther 1997;281:1381-91.

19. Lopez-Munoz FJ, Ventura R, Diaz I, Fernández-Guasti A, Tost D, Cabré F, et al. Antinociceptive effects of S-ketoprofen and other analgesic drugs in a rat model of pain induced by uric acid. J Clin Pharmacol 1998;38:11S-21S.

20. Prochazkova M, Dolezal T, Sliva J, Krsiak M. Different patterns of spinal cyclooxygenase-1 and cyclooxygenase-2 mRNA expression in inflammatory and postoperative pain. Basic Clin Pharmacol Toxicol 2006;99:173-7. [CrossRef]

21. Zhu X, Conklin DR, Eisenach JC. Preoperative inhibition of cyclooxygenase- 1 in the spinal cord reduces postoperative pain. Anesth Analg 2005;100:1390-3. [CrossRef]

22. Miranda HF, Prieto JC, Pinardi G. Spinal synergy between nonselective cyclooxygenase inhibitors and morphine antinociception in mice. Brain Res 2005;1049:165-70. [CrossRef]

23. Ossipov MH, Jerussi TP, Ren K, Sun H, Porreca F. Differential effects of spinal (R)-ketoprofen and (S)-ketoprofen against signs of neuropathic pain and tonic nociception: evidence for a novel mechanism of action of (R)-ketoprofen against tactile allodynia. Pain 2000;87:193-9. [CrossRef]

24. Abram SE, Mampilly GA, Milosavljevic D. Assessment of the potency and intrinsic activity of systemic versus intrathecal opioids in rats. Anesthesiology 1997;87:127-34. [CrossRef]

25. Martin TJ, Zhang Y, Buechler N, Conklin DR, Eisenach JC. Intrathecal morphine and ketorolac analgesia after surgery: comparison of spontaneous and elicited responses in rats. Pain 2005;113:376-85. [CrossRef]

26. Mazario J, Roza C, Herrero JF. The NSAID dexketoprofen trometamol is as potent as $\mu$ opioids in the depression of windup and spinal cord nociceptive reflexes in normal rats. Brain Res 1999;816:512-7. [CrossRef] 